\title{
Failure of steroid regulation of the MMTV promoter in a small cell lung cancer cell line is caused by a DNA sequence flanking the glucocorticoid response element
}

\author{
T T Huynh ${ }^{1}$, D W Ray ${ }^{1}$, I J Brogan ${ }^{2}$, A Stevens ${ }^{1}$, J R E Davis ${ }^{1}$ \\ and A White ${ }^{1,2}$ \\ ${ }^{1}$ Endocrine Sciences Research Group, Faculty of Medicine, University of Manchester, Manchester M13 9PT, UK \\ ${ }^{2}$ School of Biological Sciences, University of Manchester, Manchester M13 9PT, UK \\ (Requests for offprints should be addressed to A White, Endocrine Sciences Research Group, School of Biological Sciences, Stopford Building, \\ University of Manchester, Manchester M13 9PT, UK; Email: awhite@man.ac.uk)
}

\begin{abstract}
We have previously described a panel of human small cell lung carcinoma (SCLC) cell lines that have profound glucocorticoid resistance, resulting from various molecular defects in glucocorticoid signalling. However, in one SCLC cell line, CORL103, the cause of the resistance is unknown. These cells are refractory to dexamethasone stimulation of MMTV even when exogenous wild-type glucocorticoid receptor (GR) is co-transfected. This is in contrast to cell lines DMS79 and CORL24 where resistance is overcome by transfection of the wild-type receptor. Sequencing of the GR from CORL103 cells revealed two point mutations, but neither of these induced dominant negative activity. Steroid hormone resistance extended to mineralocorticoid and progesterone receptor (MR, PR) activation of MMTV-luc, whereas oestrogen and thyroid hormone receptor transactivation were normal.

A simpler reporter, TAT3-luc, containing three copies of the tyrosine aminotransferase glucocorticoid response
\end{abstract}

element (GRE), was responsive when transfected into CORL103 cells with GR, MR and PR expression vectors and activated with their respective ligands. Similarly, pHH-luc and pAH-luc (truncated MMTV variants containing the GRE region, both derived from a different strain of MMTV), were effectively transactivated with dexamethasone. This suggests that the minor changes in the flanking sequence of the MMTV promoter are critically important in determining steroid responsiveness in CORL103 cells. We propose that minor differences in MMTV may determine recruitment of co-factors, which destabilise GR binding to the MMTV GREs. These findings represent a new, selective, model of glucocorticoid resistance that may explain specific cell and target gene differences in glucocorticoid sensitivity.

Journal of Endocrinology (2002) 172, 295-302

\section{Introduction}

We have previously described a panel of human small cell lung carcinoma (SCLC) cell lines as in vitro models of the ectopic adrenocorticotrophic hormone (ACTH) syndrome (Stewart et al. 1989, White et al. 1989). Patients with the ectopic ACTH syndrome have tumours which secrete ACTH-related peptides (Stewart et al. 1994). This syndrome can be distinguished from the ACTH excess of pituitary-dependent Cushing's disease because the ACTH-related peptide production is resistant to suppression by glucocorticoids. This glucocorticoid resistance is so characteristic of the ectopic ACTH syndrome that a high-dose dexamethasone suppression test is commonly used as a diagnostic tool.
Glucocorticoid resistance is also a characteristic feature of these SCLC cell lines, which secrete the ACTH precursors, pro-opiomelanocortin and pro-ACTH, and display resistance to suppression by hydrocortisone (Clark et al. 1990). For one SCLC cell line, DMS79, failure to respond to glucocorticoid results from lack of expression of glucocorticoid receptor $\alpha(G R \alpha)$ (Ray et al. 1994) with alternative production of the GR splice variant, GR $\delta$ (Gaitan et al. 1995). In a second SCLC cell line, CORL24, we have shown that GR signalling is impaired due to a point mutation in the DNA binding domain (Ray et al. 1994). However, insensitivity to glucocorticoids in both these cell lines can be overcome by overexpressing exogenous wild-type (wt) GR $\alpha$ (Ray et al. 1994). For a third SCLC cell line, CORL103, aberrant glucocorticoid 
signalling cannot be corrected by co-transfection of the wt GR $\alpha$. CORL103 cells bind glucocorticoids with normal affinity $\left(K_{\mathrm{d}}=5 \mathrm{nM}\right)$, comparable to pituitary corticotroph AtT20 cells (Clark et al. 1990). However, transactivation of the MMTV promoter was not induced even by high doses of dexamethasone (Ray et al. 1994), indicating profound glucocorticoid resistance despite apparently normal GR expression.

As the SCLC cell line, CORL103, appears to have a novel form of glucocorticoid resistance we have now examined the possible molecular mechanism in detail. We found no evidence for a dominant negative mutation in the endogenous GR. Demonstration of normal transcriptional signalling by oestrogen receptor (ER) and thyroid hormone receptor (TR) indicated that related nuclear hormone receptors could function on their respective response elements. However, transfected progesterone receptor $(\mathrm{PR})$ and mineralocorticoid receptor (MR) failed to mediate transactivation of the MMTV promoter. By using a series of glucocorticoid response element (GRE)containing reporter gene constructs, we demonstrated that very minor changes in the GRE flanking sequence in the MMTV promoter were critical in determining steroid responsiveness in CORL103 cells. Our data indicate that even single nucleotide changes can dramatically silence GR regulation of transcription. We propose that this mechanism could underlie differential cell type specific and target gene specific responsiveness to glucocorticoids.

\section{Materials and Methods}

Cell culture

CORL103 and CORL24 cells were derived from pathologically confirmed SCLC, and were a gift from Dr P Twentyman (UKCCCR, Lincolns Inn Fields, London, UK). DMS79 cells, also from a patient with SCLC, were a kind gift from Dr O Pettengill (Dartmouth Medical School, Hanover, NH, USA). Cells were grown as previously described (Clark et al. 1990), using RPMI-1640 medium (Gibco, Paisley, Scotland), supplemented with $2 \cdot 5 \%$ fetal calf serum (FCS; Harlan Seralab, Loughborough, Leics, UK), $10 \mathrm{mM}$ HEPES buffer (Gibco), $4 \mathrm{mM}$ glutamine, $1 \mathrm{nM}$ sodium pyruvate, $10 \mathrm{mg} / \mathrm{ml}$ human transferrin (Sigma, Poole, Dorset, UK), $5 \mu \mathrm{g} / \mathrm{ml}$ insulin, and $3 \times 10^{-8} \mathrm{M}$ sodium selenite, termed RTIS medium (Ray et al. 1996).

Cos 7 cells (ECACC, Porton Down, Wilts, UK), HeLa cells (a gift from Dr M Needham, AstraZeneca Pharmaceuticals, Alderley Edge, Cheshire, UK) and ROS 17/2.8 rat osteosarcoma cells (a gift from Dr G Williams, Hammersmith Hospital, London, UK) were cultured in DMEM containing Glutamax (Gibco) and supplemented with 10\% FCS. No antibiotics were used. Cells were incubated at $37^{\circ} \mathrm{C}$ in an atmosphere containing $5 \%$ $\mathrm{CO}_{2}$.

\section{Plasmid constructs}

The construction of pMMTV-luc has been described previously (Ray et al. 1996). pAH-luc and pHH-luc were kindly donated by Dr S Nordeen (University of Colorado Medical Centre, Denver, CO, USA) (Grimm \& Nordeen 1999), and pTAT3-luc by Dr K Yamamoto (UCSF, San Francisco, CA, USA) (Iniguez-Lluhi et al. 1997). pcDNA3-hGR $\alpha$, pcDNA3, pCMV- $\beta$ gal, pSEO$\mathrm{PR}, \mathrm{pSEO}-\mathrm{ER}$ and 3 ERE-luc were generously provided by Dr M Needham. pMal-TK-luc and TR- $\beta 1$ were gifts from Prof. V K K Chatterjee (Addenbrookes Hospital, Cambridge, UK) and Dr G Williams (London, UK) respectively.

\section{PCR cloning and sequencing of $G R$}

Total RNA was isolated using RNAzol. A 780 bp product from GR $\alpha$ mRNA was amplified from CORL103 cells by reverse transcription-PCR using a sense $5^{\prime}$ primer $\left(5^{\prime}\right.$ tgtatgtttcctctgagtta- $3^{\prime}$ ) specific to exon 7 of the GR and an anti-sense $3^{\prime}$ primer $\left(5^{\prime}\right.$ - ctagaaaatttcatccacaactg- $\left.3^{\prime}\right)$ specific to the proximal $3^{\prime} \mathrm{UTR}$ of exon $9 \alpha$. PCR conditions were as follows: 1 cycle at $94{ }^{\circ} \mathrm{C}, 5 \mathrm{~min}, 35$ cycles at $94{ }^{\circ} \mathrm{C}, 30 \mathrm{~s}$, $54{ }^{\circ} \mathrm{C}, 30 \mathrm{~s}, 72{ }^{\circ} \mathrm{C}, 5 \mathrm{~min}, 1$ cycle at $72{ }^{\circ} \mathrm{C}, 100 \mathrm{~min}, 4^{\circ} \mathrm{C}$, $2 \mathrm{~min}$. The PCR products were resolved on $1.2 \%$ agarose gel. The $780 \mathrm{bp}$ product was excised from the gel and sequenced using an ABI Prism 373 machine.

\section{Transient transfection}

Adherent cells Subconfluent cells $(10 \mathrm{ml})$ were plated at a density of $1 \times 10^{5}$ cells $/ \mathrm{ml}$ into $10-\mathrm{cm}$ diameter plates (Costar, High Wycombe, UK) and incubated overnight. Each plate was transfected with LipofectAMINE plus (Gibco) according to the manufacturer's instructions. Unless otherwise specified, $1 \mu \mathrm{g}$ promoter was transfected with or without $0.5 \mu \mathrm{g}$ receptor. Control of transfection efficiency was determined with co-transfection of $1 \mu \mathrm{g}$ CMV- $\beta$ gal. Transfected cells were plated onto $12-$ or $24-w e l l$ plates on day 3. Cells were washed once with PBS after $20 \mathrm{~h}$ of steroid hormone treatment and then harvested by lysing with $150 \mu \mathrm{l}$ lysis buffer $(25 \mathrm{mM}$ Tris phosphate, $\mathrm{pH} 7 \cdot 8,10 \mathrm{mM} \mathrm{MgCl} 2,0 \cdot 1 \mathrm{mg} / \mathrm{ml} \mathrm{BSA}, 15 \%$ glycerol, $1 \%$ Triton X-100, and $1 \mathrm{mM}$ EDTA), as described (Ray et al. 1996). One hundred microlitres lysate were used to determine the luciferase activity by measuring in a Berthold Lumat LB9501 luminometer in the presence of $0.8 \mathrm{mM}$ ATP and $0.3 \mathrm{mM}$ D-luciferin. Thirty microlitres lysate were used to determine $\beta$-galactosidase activity by O-nitrophenyl- $\beta$-D-galactopyranoside (ONPG) assay as a measure of transfection efficiency.

For transfection with TR and ER, cells were incubated in medium containing fetal calf serum, which had been stripped for $24 \mathrm{~h}$ with BioRad AgX500 resin, to remove thyroid hormone and oestradiol. 
SCLC cells Cells $\left(2 \times 10^{6}\right)$, washed once with PBS, were co-transfected with $2 \mu \mathrm{g}$ promoter, $4 \mu \mathrm{g} C M V-\beta g a l$ with or without $2 \mu \mathrm{g}$ receptor in $2 \mathrm{ml}$ supplement-free RPMI containing $30 \mu \mathrm{l}$ DMRIEC (Gibco) for $24 \mathrm{~h}$, unless otherwise stated. Cells were treated with or without $100 \mathrm{nM}$ steroid hormone. Cells were harvested and lysed as for adherent cells (Ray et al. 1996). Triplicate transfections were carried out during each experiment and each experiment was repeated on three separate occasions.

\section{Statistical analysis}

Results are presented as means and standard deviations of at least three separate transfections in each experiment and all experiments were repeated on at least three separate occasions. Student's t-tests were performed using SPSS software (Chicago, IL, USA).

\section{Potential transcription factor binding sites}

To analyse DNA sequences for potential transcription factor binding sites, the TFSEARCH program was used (Y Akiyama). This programme is available from the Internet at location http://pdap1.trc.rwcp.or.jp/research/ $\mathrm{db} /$ TFSEARCH.html. This program relies on the TRANSFAC database of transcription factors to create a profile of all potential DNA binding factors that may bind to a specific sequence.

\section{Results}

Failure of transactivation of the MMTV promoter in CORL103 cells despite expression of functionally normal GR

In transient transfection experiments, there was no induction of the MMTV-luc reporter gene in CORL103 cells in the presence of $100 \mathrm{nM}$ dexamethasone, either with or without co-transfection of the wild-type GR $\alpha$ (Fig. 1a). In contrast, in Cos 7 cells transfected with MMTV-luc and exogenous GR, dexamethasone stimulated the MMTV promoter up to $15 \cdot 7$-fold (Fig. 1b). This induction was inhibited by the glucocorticoid antagonist RU38486 (Fig. 1b).

Reverse transcription-PCR established the presence of GR $\alpha$ mRNA in CORL103 cells (Fig. 2a) and sequencing of the full-length GR cDNA from multiple independent clones revealed two point mutations. A single nucleotide $\mathrm{TC}_{2430}$ substitution did not alter codon usage. However, a $\mathrm{GA}_{655}$ mutation predicts a GlySer conversion at amino acid 175, located within the GR $\tau 1$ domain (Fig. 2b) found to be present in 25\% of clones (Fig. 2c). A GR-Ser ${ }_{175}$ expression vector was constructed to assess the transcriptional activity of this latter mutant in Cos 7 cells. There was no significant difference in activity (data not a) COR L103 cells

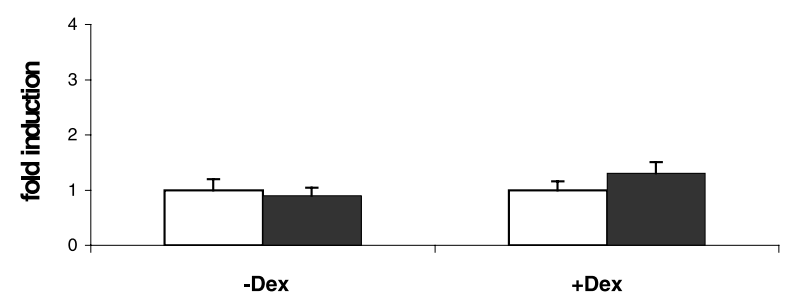

b) $\operatorname{Cos} 7$ cells

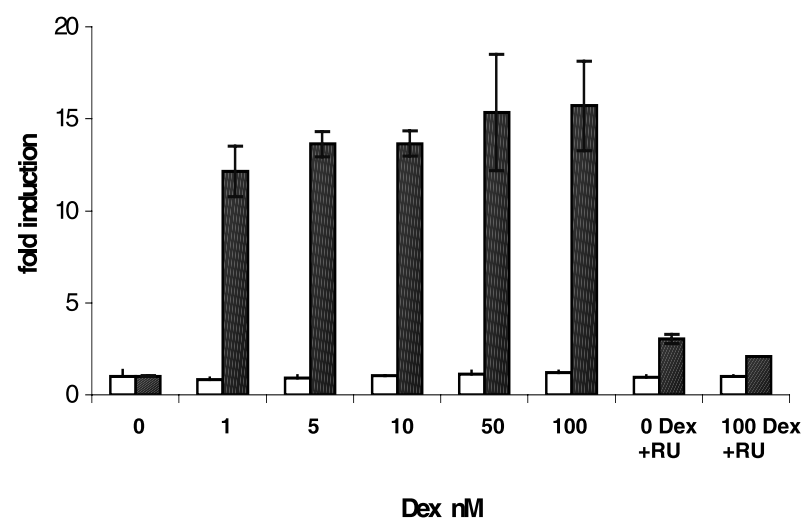

Figure 1 Comparison of the transactivation of MMTV-luc in CORL103 and GR receptorless Cos 7 cells. (a) CORL103 cells $\left(2 \times 10^{6}\right)$ were co-transfected with $2 \mu \mathrm{g}$ MMTV-luc, $4 \mu \mathrm{g}$ CMV- $\beta$ gal and either $2 \mu \mathrm{g}$ GR $\alpha$ (solid bars) or pcDNA3 as control (open bars). Transfected cells were treated with or without $100 \mathrm{nM}$ dexamethasone (Dex) for $20 \mathrm{~h}$. Triplicate transfections were performed on three different occasions. (b) Subconfluent Cos 7 cells were seeded at a density of $1 \times 10^{6}$ cells and incubated overnight. Cells were co-transfected with $1 \mu \mathrm{g}$ MMTV-luc, $1 \mu \mathrm{g}$ CMV- $\beta$ gal with $0.5 \mu \mathrm{g}$ GR $\alpha$ (solid bars) or pcDNA3 (open bars). Cells were treated with 0-100 nM dexamethasone, or RU38486 (RU; $100 \mathrm{nM})$.

shown), implying that the $\operatorname{Ser}_{175}$ mutation was not the cause of glucocorticoid resistance in this SCLC cell line.

\section{Signalling by other nuclear receptors}

As CORL103 cells failed to support glucocorticoid signalling both by endogenous GR and by overexpressed exogenous GR, we examined whether the closely related mineralocorticoid receptor (MR) or progesterone receptor (PR) could transactivate the MMTV promoter in these cells. In addition, we examined whether more distantly related nuclear receptors were functionally active, in order to target the problem to the shared DNA response element (for PR, GR, MR) or to shared co-activators (ER, TR).

Thyroid hormone $\left(\mathrm{T}_{3} ; 100 \mathrm{nM}\right)$ induced Mal-TK-luc reporter gene expression in the presence of co-transfected thyroid hormone receptor (TR $\beta 1$ ), and oestradiol $(100 \mathrm{nM})$ induced oestrogen response element (ERE)-luc expression in the presence of co-transfected oestrogen 
(a)

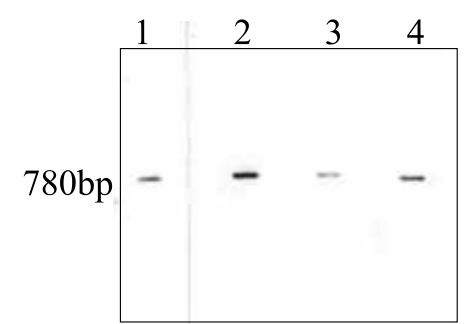

(b)

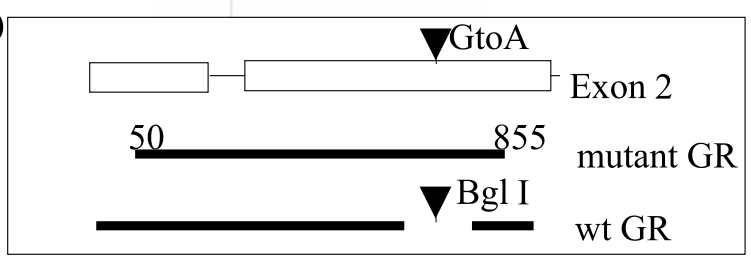

(c)

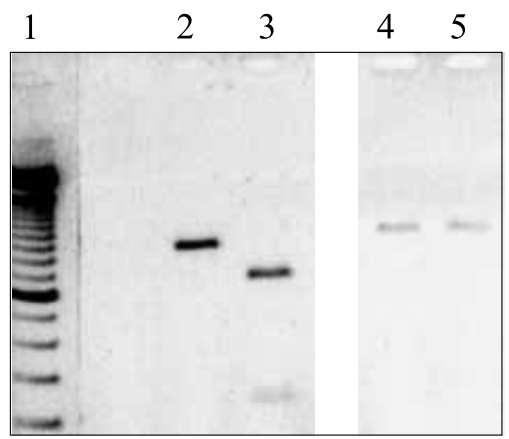

Figure 2 (a) Expression of the glucocorticoid receptor (GR) mRNA. Sense primers and anti-sense primers complimentary for exon 7 and $9 \alpha$ of GR were used to identify a product of 780 bp in length. Lane 1, HeLa cDNA; lane 2, CORL103 cDNA; lane 3, CORL24 cDNA; lane 4, DMS79 cDNA. (b) Schematic diagram of point mutations identified in CORL103 cells. RNA from CORL103 cells was amplified by RT-PCR between nucleotides 50-855, and cloned into a T-vector. Sequencing identified a G-to-A point mutation in $25 \%$ of clones. This converts amino acid 175 from glycine to serine. It is predicted that a Bgl1 site in the wild-type GR would be abolished in the mutant GR. (c) Endogenous GR point mutations in CORL103 cells. PCR products of CORL103 were examined for the introduction of a G-to-A conversion at 655. RNA was reverse transcribed and amplified by PCR. The PCR products were cloned into a $\mathrm{T}$ vector, and the insert from individual colonies was analysed for the presence of the Bgl 1 site. Lane 1, $1 \mu \mathrm{g}$ Gibco ladder $1000 \mathrm{bp}$; lane 2, uncut insert from HeLa cells; lane 3, Bgl1 digested insert from HeLa cells; lane 4, uncut insert from CORL103; lane 5, Bgl1 digested insert from CORL103 cells.

receptor (ER) (Table 1). In contrast, the MMTV promoter was unresponsive not only to dexamethasone but also to hydrocortisone $(100 \mathrm{nM})$, aldosterone $(100 \mathrm{nM})$ and progesterone $(100 \mathrm{nM})$, despite co-expression of the respective receptors, GR, MR and PR. All three receptor expression vectors conferred appropriate hormone sensitivity on Cos 7 cells and the SCLC cell lines, CORL24 and DMS79 (data not shown). Therefore, there is a failure of signalling by all three steroid receptors which are
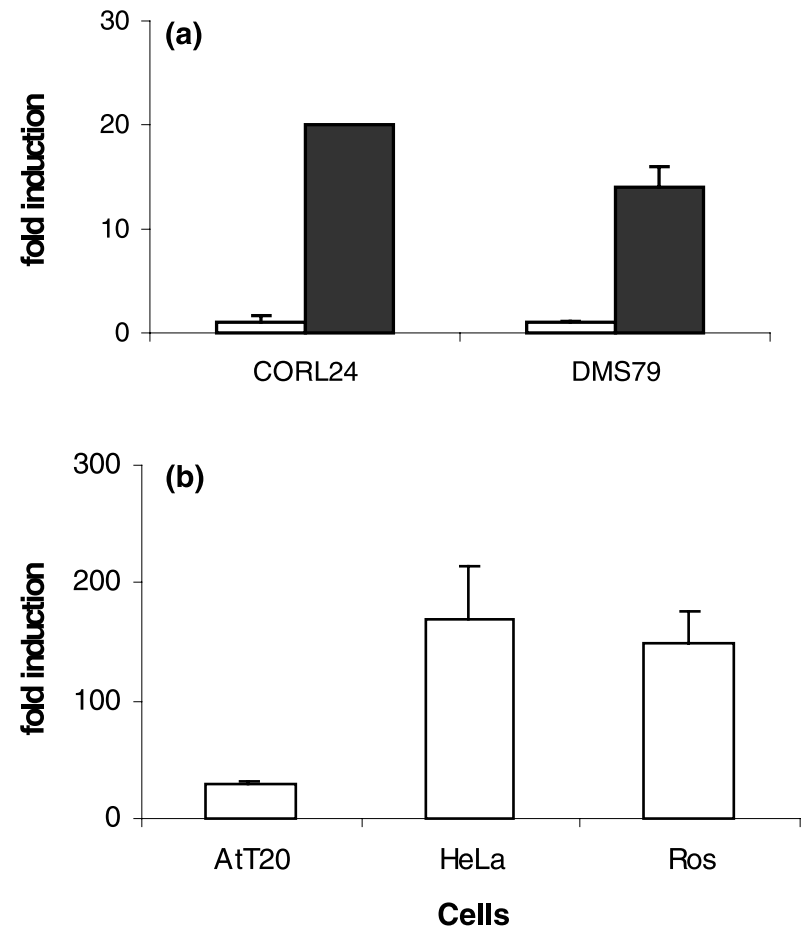

Figure 3 Transactivation of MMTV-luc in other cell lines. Small cell lung carcinoma (SCLC) cell lines CORL24 and DMS79 were co-transfected with MMTV-luc $(2 \mu \mathrm{g})$, and CMV- $\beta$ gal $(4 \mu \mathrm{g})$, either with (solid bars) or without (open bars) pcDNA 3 hGR $(2 \mu \mathrm{g})$.

Other cells that express functional endogenous GR (AtT20, mouse pituitary corticotroph adenoma cells; HeLa, human epithelial carcinoma cells; and ROS $17 / 2 \cdot 8$, rat osteosarcoma cells) were transfected with $2 \mu \mathrm{g}$ MMTV-luc without exogenous GR. Transfected cells were divided into treated (dexamethasone; $100 \mathrm{nM}$ ) or controls. Cells were harvested after $16 \mathrm{~h}$ and luciferase and CMV- $\beta$ gal activity determined. Luciferase was corrected for CMV- $\beta$ gal activity and the results expressed as fold induction over control.

capable of binding to the MMTV hormone response element.

In contrast to the CORL103 cells, robust transactivation (10- to 200-fold) of the MMTV promoter was observed in glucocorticoid sensitive cell lines (AtT20, HeLa and ROS 17/2.8) and in resistant cell lines transfected with exogenous wild-type glucocorticoid receptor (CORL24 and DMS79) (Fig. 3). This suggests that the failure to transactivate the MMTV promoter was specific to CORL103 cells.

\section{GR transactivation of other promoters}

As the MMTV promoter was not regulated by glucocorticoids in CORL103 cells, we assessed a simple GRE construct consisting of three copies of the tyrosine aminotransferase GRE upstream of a minimal promoter (TAT3-luc) (Iniguez-Luhi et al. 1997). Dexamethasone 
Table 1 Nuclear receptor regulation of reporter genes. Cells were co-transfected with the reponse elements, MMTV or ERE or TRE linked to luciferase $(2 \mu \mathrm{g})$ and mineralocorticoid receptor $(\mathrm{MR})$, progesterone receptor (PR), oestrogen receptor (ER) or thyroid hormone receptor (TR) all at $2 \mu \mathrm{g}$. CMV- $\beta$ gal $(4 \mu \mathrm{g})$ reporter gene was used as a control of transfection efficiency. Transfected cells were treated with dexamethasone (Dex), hydrocortisone $(\mathrm{Hc})$, aldosterone (Aldo), progesterone $(\mathrm{P})$, thyroid hormone $\left(\mathrm{T}_{3}\right)$, or oestradiol $\left(\mathrm{E}_{2}\right)$ at $100 \mathrm{nM}$ for 20 h. ${ }^{*} P<0 \cdot 05$ compared to control.

\begin{tabular}{|c|c|c|c|c|c|c|c|c|}
\hline & \multicolumn{4}{|l|}{ MMTV } & \multicolumn{2}{|c|}{ MAL-Tk luc } & \multicolumn{2}{|l|}{ ERE-luc } \\
\hline & - receptor & $+\mathrm{GR}$ & $+M R$ & $+P R$ & $-\mathrm{TR}$ & $+\mathrm{TR}$ & $-E R$ & $+\mathrm{ER}$ \\
\hline $\mathrm{Hc}$ & $1 \pm 0 \cdot 04$ & & $1 \pm 0 \cdot 19$ & & & & & \\
\hline Aldo & $1 \pm 0.07$ & & $1 \pm 0 \cdot 13$ & & & & & \\
\hline $\mathrm{P}$ & $1 \pm 0 \cdot 12$ & & & $1 \pm 0 \cdot 10$ & & & & \\
\hline
\end{tabular}

did not significantly activate TAT3-luc in CORL103 cells in the absence of co-expressed GR $\alpha$, implying that the endogenous GR was indeed non-functional at this promoter. However, co-expression of exogenous GR $\alpha$ did allow glucocorticoid transactivation of TAT3-luc in CORL103 cells (Fig. 4a), with the rank order of potency of glucocorticoids being dexamethasone >triamcinolone> hydrocortisone $=$ prednisolone - the rank order predicted for GR $\alpha$ (data not shown).

These results suggested that the GREs within the MMTV promoter were inactive in CORL103 cells. Two further MMTV promoter constructs were therefore studied: $\mathrm{pHH}$, a truncated $\mathrm{C}_{3} \mathrm{H}$ MMTV variant consisting only of the GRE-containing regions without flanking DNA, and $\mathrm{pAH}$, a longer $\mathrm{C}_{3} \mathrm{H}$ construct containing flanking DNA (see schematic diagram in Fig. 5). In the presence of co-transfected GR, both $\mathrm{pHH}$ and $\mathrm{pAH}$ were induced by $100 \mathrm{nM}$ dexamethasone in CORL103 cells (Fig. 4b).

As both $\mathrm{pHH}$ and $\mathrm{pAH}$, but not MMTV-luc, were efficiently transactivated by glucocorticoid treatment, we compared their promoter structures. All three constructs utilise the pXP2 backbone (Grimm \& Nordeen 1999) and include the well-characterised GRE elements (Beato 1989). Strain variation may exist in the MMTV genome: the $\mathrm{pAH}$ and $\mathrm{pHH}$ constructs were derived from the $\mathrm{C} 3 \mathrm{H}$ strain of MMTV (Grimm \& Nordeen 1999) whereas the MMTV-luc was derived from the plasmid pMSG-CAT (Amersham Pharmacia, Little Chalfont, UK). Therefore, we undertook detailed sequence comparison of the pAH and MMTV promoters (Fig. 5) and identified a number of single nucleotide differences. One of these changes, a putative consensus $\mathrm{C} / \mathrm{EBP} \beta$ site in MMTV near to the GREs, was converted to an NF1 site in the pAH-luc construct, but the others do not disrupt or introduce consensus transcription factor binding sites (Fig. 5).

\section{Discussion}

Glucocorticoid resistance may be inherited or acquired and is increasingly being recognised (Ray et al. 1996). In man, inherited glucocorticoid resistance has been attributed to mutations in the gene encoding the GR (Hurley et al. 1991, Karl et al. 1993, Malchoff et al. 1993). In comparison, acquired somatic mutation of the GR giving rise to glucocorticoid resistance has been extensively documented in haematopoietic malignancy (Norgaard \& Poulsen 1991). Variations in glucocorticoid sensitivity may be dynamically regulated in nontransformed cells in the absence of GR mutation, and understanding possible mechanisms for such variation may have important consequences for human health.

In previous studies exploring the molecular basis of glucocorticoid resistance in the ectopic ACTH syndrome, we described defects in endogenous GR structure and function in two SCLC cell lines (Ray et al. 1994, 1996). In this study of CORL103 cells, we found that neither the endogenous GR nor overexpressed exogenous GR activated the MMTV promoter. The resistance of MMTVluc to steroid induction in these cells also extended to other related steroid hormone receptors including the MR and PR. In contrast, transfected ER effectively activated appropriate reporter genes despite sharing similar coactivators to GR. The more distantly related $T_{3} R$ was also able to function normally in these cells. These data suggest that the MMTV GRE sequences were not functional enhancers in CORL103 cells.

The finding that a simple glucocorticoid-responsive promoter construct (TAT3-luc) was transactivated by co-expressed GR in CORL103 cells indicated that the GR was expressed and was capable of regulating transcription in CORL103 cells. The GREs within TAT promoter constructs function synergistically upstream of a minimal 
(a)

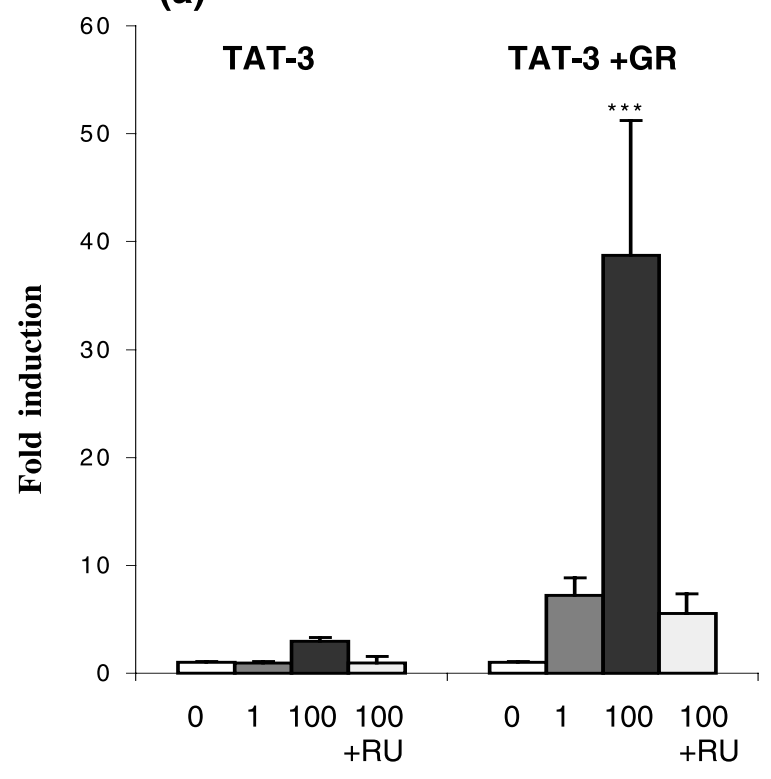

\section{Dexamethasone (nM)}

(b)

$\mathrm{PHH}+\mathrm{GR}$

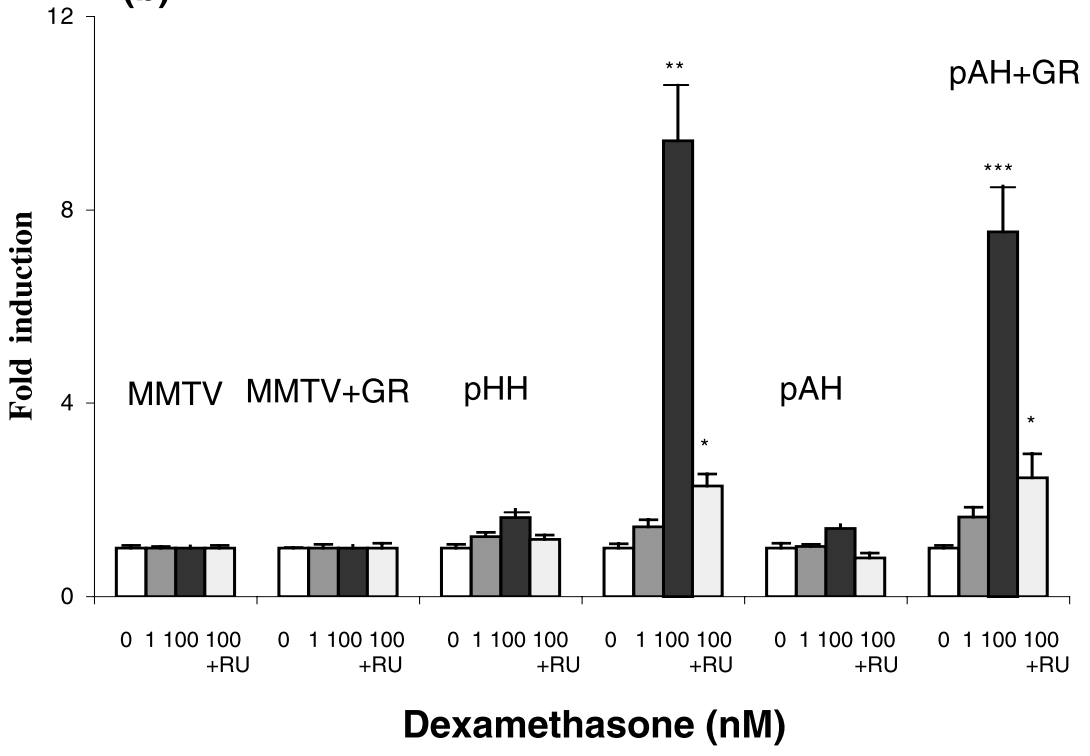

Figure 4 Comparison of the transactivation of different GRE promoters in CORL103 cells. (a) Cells were transfected with the TAT-3-luc with or without GR $\alpha$ and treated with 0-100 nM dexamethasone or $100 \mathrm{nM}$ RU38486 (RU) + $100 \mathrm{nM}$ dexamethasone. (b) CORL103 cells were transfected with MMTV, $\mathrm{pHH}$ or $\mathrm{pAH}$ with or without $\mathrm{GR} \alpha$ and treated with dexamethasone and RU38486 as above. Data represent means \pm S.D. of 3 separate transfections in each experiment and each experiment was repeated on three different occasions with similar results. ${ }^{*} P<0 \cdot 05,{ }^{* *} P<0 \cdot 01,{ }^{* *} P<0 \cdot 001$. 


\section{GRE Half Sites}

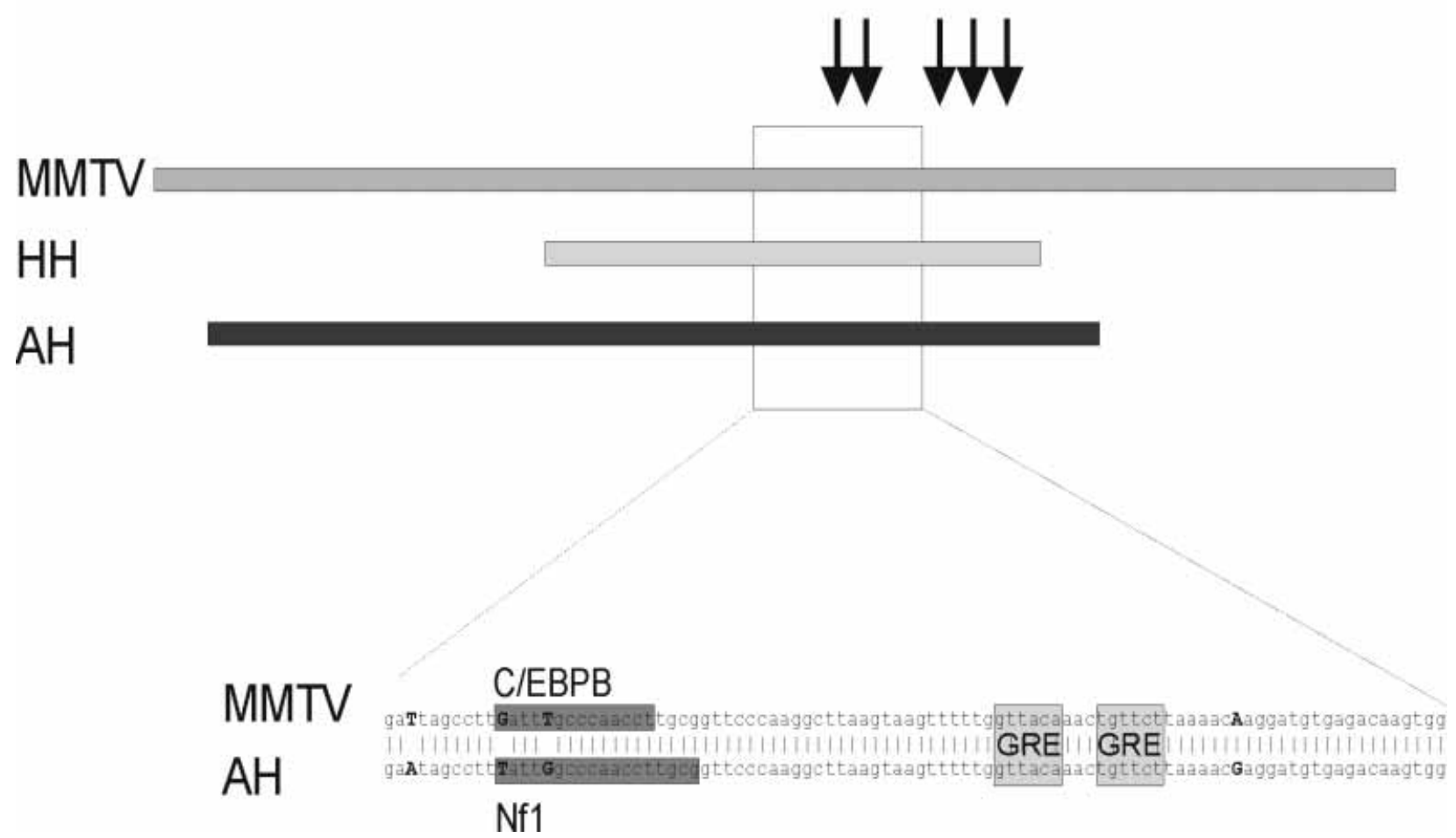

Figure 5 Schematic diagram showing the location of glucocortocoid response element (GRE) and nucleotide differences of the three reporter constructs used in these studies. MMTV has a $5^{\prime}$ putative C/EBP $\beta$ site (boxed) and both $\mathrm{HH}$ and AH have a common NF1 site generated by a 2-nucleotide substitution (boxed).

promoter (Jantzen et al. 1987) although it is unclear how their interaction is achieved (Iniguez-Lluhi et al. 1997). However, hormonal induction of the MMTV promoter requires not only binding of GR to GREs but also binding of other transcription factors to flanking sequences (Bruggemeier et al. 1991).

Glucocorticoid can induce transactivation of $\mathrm{pHH}$-luc and pAH-luc but not MMTV promoter

Interestingly, the failure of MMTV activation in CORL103 cells may be reversed by relatively small changes in the sequence of the promoter. Figure 4 shows that although endogenous and exogenous receptors in CORL103 cells are unable to stimulate activity of intact MMTV promoter, glucocorticoid signalling by exogenous $\mathrm{GR} \alpha$ is functional at $\mathrm{pHH}$, a truncated MMTV promoter, possessing only the GRE containing region. A longer construct containing additional flanking DNA (pAH-luc) is also glucocorticoid responsive. These observations suggest that the GRE flanking DNA of the full length pMMTV-luc recruits a protein in CORL103 cells which then inhibits activation by the GR, perhaps by influencing
DNA occupancy, or recruitment of co-activators. Alternatively, such a DNA binding factor may alter occupancy of other enhancer elements within the GRE region of the MMTV promoter in such a way as to repress the promoter.

Guido et al. (1996) showed that point mutation of GR at amino acid 442 prevented transcriptional activation at the MMTV promoter although transcription of the TAT3 promoter still occurred. This GR mutant efficiently bound to both GRE sequences and activated transcripts from the MMTV GREs when they were isolated from the rest of the promoter. This implied that GR interacted with other bound proteins at the MMTV promoter which were absent in the simpler TAT3 promoter. Thus, differences in GRE flanking sequence between TAT3 and MMTV may determine different demands on the receptor for transactivation; binding of the GR to GRE sites on MMTV may lead to a conformational change in GR structure which differs from that produced by its interaction with the TAT3 promoter.

Results from this study suggest that the 'glucocorticoid resistant phenotype' in CORL103 cells is complex. The cells are resistant to glucocorticoids in the absence of co-transfected GR expression vector, but when GR is 
overexpressed, MMTV remains refractory to glucocorticoid induction. This may be due to the expression of an inhibitory protein or lack of a functional co-activator that is required for MMTV transactivation by GR. Support for this conclusion comes from the failure of $\mathrm{MR}$ and $\mathrm{PR}$ to regulate the MMTV-luc reporter gene in CORL103 cells, the ability of exogenous GR to regulate $\mathrm{pAH}-\mathrm{luc}, \mathrm{pHH}-$ luc and TAT3-luc, and the identification of sequence differences between the closely related pAH-luc and MMTV-luc. As natural GREs often occur close to other transcription factor binding sites, these observations build on earlier work showing that GR function can be regulated by non-GR factors, for example AP-1 on the plfg composite GRE (Diamond et al. 1990) or C/EBP (Schule et al. 1988, Strahle et al. 1988). Furthermore, recent work has indicated the importance of other, unidentified factors capable of limiting synergistic transactivation (IniguezLluhi \& Pearce 2000).

The importance of cell specific factors interacting with GRE flanking sequences and so modulating the hormone responsiveness of promoters has not been thoroughly explored. We propose that this may be a general mechanism whereby cell-type specificity of hormone action may be conferred. As such, this mechanism has major implications for understanding how the ubiquitous glucocorticoid/GR system can achieve specificity of action in diverse tissues.

\section{Acknowledgements}

We are grateful to the MRC for a $\mathrm{PhD}$ studentship to T T Huynh. D W Ray is a Glaxo-Wellcome Fellow. J Sampayo provided expert technical help. We are grateful to Salford Royal Hospitals Trust and Central Manchester Healthcare Trust for additional financial support.

\section{References}

Beato M 1989 Gene regulation by steroid hormones. Cell 56 335-344. Bruggemeier U, Kalff U, Franke U, Scheidereit C \& Beato M 1991 Ubiquitous transcription factor OTF-1 mediates induction of the MMTV promoter through synergistic interaction with hormone receptors. Cell 64 565-572.

Clark AJ, Stewart MF, Lavender PM, Farrell W, Crosby SR, Rees LH \& White A 1990 Defective glucocorticoid regulation of proopiomelanocortin gene expression and peptide secretion in a small cell lung cancer cell line. Journal of Clinical Endocrinology and Metabolism 70 485-490.

Diamond MI, Miner JN, Yoshinaga SK \& Yamamoto KR 1990 Transcription factor interactions: selectors of positive or negative regulation from a single DNA element. Science 249 1266-1272.

Gaitan D, DeBold CR, Turney MK, Zhou P, Orth DN \& Kovacs WJ 1995 Glucocorticoid receptor structure and function in an adrenocorticotropin-secreting small cell lung cancer. Molecular Endocrinology 9 1193-1201.
Grimm SL \& Nordeen SK 1999 Luciferase reporter gene vectors for analysis of promoters and enhancers. Biotechniques 27 220-222.

Guido EC, Delorme EO, Clemm DL, Stein RB, Rosen J \& Miner JN 1996 Determinants of promoter-specific activity by glucocorticoid receptor. Molecular Endocrinology 10 1178-1190.

Hurley DM, Accili D, Stratakis CA, Karl M, Vamvakopoulos N, Rorer E, Constantine K, Taylor SI \& Chrousos GP 1991 Point mutation causing a single amino acid substitution in the hormone binding domain of the glucocorticoid receptor in familial glucocorticoid resistance. Journal of Clinical Investigation 87 680-686.

Iniguez-Lluhi JA \& Pearce D 2000 A common motif within the negative regulatory regions of multiple factors inhibits their transcriptional synergy. Molecular Cell Biology 20 6040-6050.

Iniguez-Lluhi, Lou DY \& Yamamoto KR 1997 Three amino acid substitutions selectively disrupt the activation but not the repression function of the glucocorticoid receptor $\mathrm{N}$ terminus. Journal of Biological Chemistry 272 4149-4156.

Jantzen HM, Stahle U, Glass B, Stewart F \& Smidt W 1987 Cooperativity of glucocorticoid response element of tyrosine amino-transferase gene. Cell 49 29-38.

Karl M, Lamberts SW, Detera-Wadleigh SD, Encio IJ, Stratakis CA, Hurley DM, Accili D \& Chrousos GP 1993 Familial glucocorticoid resistance caused by a splice site deletion in the human glucocorticoid receptor gene. Journal of Clinical Endocrinology and Metabolism 76 683-689.

Malchoff DM, Brufsky A, Reardon G, McDermott P, Javier EC, Bergh CH, Rowe D \& Malchoff CD 1993 A mutation of the glucocorticoid receptor in primary cortisol resistance. Journal of Clinical Investigation 91 1918-1925.

Norgaard P \& Poulsen HS 1991 Glucocorticoid receptors in human malignancies: a review. Annals of Oncology 2 541-557.

Ray DW, Littlewood AC, Clark AJL, Davis JRE \& White A 1994 Human small cell lung cancer cell lines expressing the proopiomelanocortin gene have aberrant glucocorticoid receptor function. Journal of Clinical Investigation 93 1625-1630.

Ray DW, Davis JRE, White A \& Clark AJL 1996 Glucocorticoid receptor structure and function in glucocorticoid-resistant small cell lung carcinoma cells. Cancer Research 56 3276-3280.

Schule R, Muller M, Otsuka Murakami H \& Renkawitz R 1988 Cooperativity of the glucocorticoid receptor and the CACCC-box binding factor. Nature 332 87-90.

Stewart MF, Crosby SR, Gibson S, Twentyman PR \& White A 1989 Small cell lung cancer cell lines secrete predominantly ACTH precursor peptides not ACTH. British Journal of Cancer 60 20-24.

Stewart PM, Gibson S, Crosby SR, Penn R, Holder R, Ferry D, Thatcher N, Phillips DR \& White A 1994 ACTH precursors characterise the ectopic ACTH syndrome. Clinical Endocrinology 40 199-204.

Strahle U, Schmid W \& Schutz G 1988 Synergistic action of the glucocorticoid receptor with transcription factors. EMBO Journal 7 3389-3395.

White A, Stewart MF, Farrell WE, Crosby PM, Lavender PM, Twentyman PR, Rees LH \& Clark AJL 1989 Pro-opiomelanocortin gene expression and peptide secretion in human small-cell lung cancer cell lines. Journal of Molecular Endocrinology 3 65-70.

Received 8 October 2001

Accepted 22 October 2001 